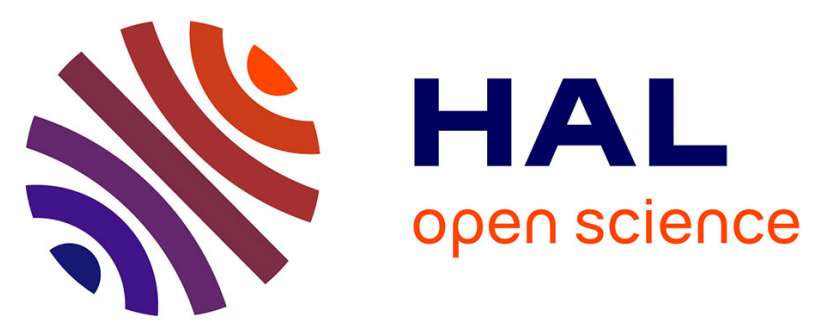

\title{
Combining Freehand Ultrasound-Based Indentation and Inverse Finite Element Modelling for the Identification of Hyperelastic Material Properties of Thigh Soft Tissues
}

Nolwenn Fougeron, Pierre-Yves Rohan, Diane Hearing, Jean-Loïc Rose, Xavier Bonnet, Hélène Pillet

\section{To cite this version:}

Nolwenn Fougeron, Pierre-Yves Rohan, Diane Hearing, Jean-Loïc Rose, Xavier Bonnet, et al.. Combining Freehand Ultrasound-Based Indentation and Inverse Finite Element Modelling for the Identification of Hyperelastic Material Properties of Thigh Soft Tissues. Journal of Biomechanical Engineering, 2020, pp.1-22. 10.1115/1.4046444 . hal-02520020

\author{
HAL Id: hal-02520020 \\ https://hal.science/hal-02520020
}

Submitted on 26 Mar 2020

HAL is a multi-disciplinary open access archive for the deposit and dissemination of scientific research documents, whether they are published or not. The documents may come from teaching and research institutions in France or abroad, or from public or private research centers.
L'archive ouverte pluridisciplinaire HAL, est destinée au dépôt et à la diffusion de documents scientifiques de niveau recherche, publiés ou non, émanant des établissements d'enseignement et de recherche français ou étrangers, des laboratoires publics ou privés. 


\title{
Combining Freehand Ultrasound-Based
}

\author{
Indentation and Inverse Finite Element
}

\section{Modelling for the Identification of Hyperelastic}

\section{Material Properties of Thigh Soft Tissues}

Nolwenn Fougeron ${ }^{1,2}$, Pierre-Yves Rohan ${ }^{1}$, Diane Hearing ${ }^{1}$, Jean-Loïc Rose ${ }^{2}$, Xavier Bonnet ${ }^{1}$, Hélène Pillet ${ }^{1}$

${ }^{1}$ Institut de Biomécanique Humaine Georges Charpak, Arts et Métiers Paristech, 151 bd de l'Hôpital, 75013 Paris,

France

${ }^{2}$ Proteor, Recherche et développement, 5 boulevard Winston Churchill, 21000 Dijon, France

Corresponding author:

Nolwenn Fougeron

LBM/Institut de Biomécanique Humaine Georges Charpak

Arts et Métiers ParisTech

151 bd de l'Hôpital 75013 Paris

E-mail: nolwenn.fougeron@ensam.eu

Keywords ( $\max 6$ ): Freehand Ultrasound, Material Properties, Soft Tissues, Contraction, Large Displacement 


\section{Abstract}

Finite Element Analysis (FEA) is a numerical modelling tool vastly employed in research facilities to analyse and predict load transmission between the human body and a medical device, such as a prosthesis or an exoskeleton. Yet, the use of Finite Element Modelling (FEM) in a framework compatible with clinical constraints is hindered by, amongst others, heavy and time-consuming assessments of material properties. Ultrasound imaging opens new and unique opportunities for the assessment of in vivo material properties of soft tissues. Confident of these advances, a method combining a freehand ultrasound probe and a force sensor was developed in order to compute the hyperelastic constitutive parameters of the soft tissues of the thigh in both relaxed (R) and contracted (C) muscles configurations. Seven asymptomatic subjects were included for the experiment. Two operators in each configuration performed the acquisitions. Inverse FEM allowed for the optimisation of an Ogden's hyperelastic constitutive model of soft tissues of the thigh in large displacement. The mean shear modulus identified for configurations $\mathrm{R}$ and $\mathrm{C}$ were respectively $3.2 \pm 1.3 \mathrm{kPa}$ and $13.7 \pm 6.5 \mathrm{kPa}$. The mean alpha parameter identified for configurations $\mathrm{R}$ and $\mathrm{C}$ were respectively $10 \pm 1$ and $9 \pm 4$. An analysis of variance showed that the configuration had an effect on constitutive parameters but not the operator. 


\section{Introduction}

Mechanical interaction of the human body with an external medical device often implies direct contact at the interface between the body and the device such as, for example, between residual limb and prosthetic socket or between lower limb and exoskeletons or orthoses. This interface is critical in order to ensure an optimal tradeoff between load transmission and both comfort and the prevention of soft tissues injuries. This is the reason why a particular attention has been paid to the mechanical behaviour of soft tissues under contact loadings in the last decade [1-3]. One way to evaluate loadings at the interface is to design subject specific Finite Element (FE) models [2,4-6]. Several barriers exist to the clinical use of these models. Amongst these, the application of subject-specific tissue material parameters is an important issue. As a matter of fact, most of the studies in the literature used nonpersonalised values from animal specimens and human cadavers [7-13], even though it has been established that variations in material properties can have a significant impact on the interface loads predicted by the model [14]. The personalisation of material properties is a highly challenging bottleneck for the whole community, more particularly in regions with high tissue thicknesses such as the thigh where to compute the geometry without deformation, complex image acquisition systems are often needed [15-18]

One way to evaluate the mechanical behaviour of soft tissues under quasi-static compression is to perform indentation tests to collect force-displacement data [18-23]. From such measurements, the extraction of material properties is not direct. The most popular method consists in using an analytic solution (or a derived method) of the Hertz contact model [20,23-26]. Using the theoretical solution to the problem associated with axisymmetric indentation proposed by Hayes et al. [27], many authors brought some insights into the mechanical response of soft tissues. In particular, Mak et al. focused on the leg, first with an apparatus composed of a linear actuator and a load cell, then using a pen sized ultrasound-based apparatus called Tissue Ultrasound Palpation System [20,25,26,28,29]. Investigations on lower limb of disabled and non-disabled subjects established that material properties were specific to the subject [25] and that the main parameters influencing the biomechanical properties of tissues were age [25,26,29], gender [25], body posture [20,25], site of indentation $[25,26]$, and muscular activity [26]. Such results are of particular relevance when studying the interaction of people with a medical device such as a prosthesis or an assistance exoskeleton where muscles are compressed or elongated and recruited during walking activity. As far as the authors are aware of, no study deals with the sensitivity of material parameters of the soft tissues of the thigh to muscular activity. 
Nonetheless, the use of the Hayes' theoretical formula is restrictive. The formula was introduced for thin infinite layers lying on a rigid support, with imposed geometries of indentor [27]. Moreover, a geometry and material-dependent factor $\kappa$ was computed for some values of indentor radius, tissue thickness and indentation depth which are not consistent with large thickness soft tissues areas such as the thigh. In addition, the Hayes' formula only allows to compute an effective Young's modulus, which is limited if used to describe the mechanical response of biological soft tissues which exhibit a highly non-linear response at large strains [30-33].

In order to overcome these issues and to identify non-linear constitutive parameters of soft tissues, one may use experimental-numerical procedures like the inverse FEM [2,34-37]. To this aim, some authors developed FE models of the leg and identified constitutive parameters of soft tissues with experimental indentation curves of force and displacement $[31,38]$. As far as the authors are aware of, very few studies of this type has been proposed for very large tissue thickness areas such as the buttock or the thigh [17,39-42]. One study provided some insights about the passive mechanical response of tissues with muscle activation but results were only provided for one subject [39]. Developed apparatus, although being relevant for research purposes, are not transferable to the clinic since they are too complex to implement. Alternatively, as detailed previously, a very promising avenue is the use of freehand ultrasound (US) that is easily transferable to the clinic

In this study, the authors present an experimental-numerical protocol, which allows to determine material properties of thigh soft tissues under external compressive loading in two configurations: relaxed and contracted muscle states. These configurations were chosen to highlight the influence of the activity state of muscles on the passive mechanical response of thigh soft tissues in contact with a medical device. Soft tissues were assumed in this contribution to be isotropic and homogeneous. 


\section{Materials and methods}

\subsection{Subjects}

After approval by the local ethics committee (Comité de Protection des Personnes CPP NX06036), seven non-disabled subjects (six men and one woman) were included in this study. Subjects were aged between 23 and 41 years old. Their body mass indices were comprised between 21.4 and $24.3 \mathrm{~kg} . \mathrm{m}^{-2}$. Subjects' data are summarised in Tab. 1.

\subsection{Experimental protocol}

\subsubsection{Experimental setup}

A custom US-based freehand indenter, illustrated in Figure 1a, was conceived by combining a $200 \mathrm{~N}$ force sensor (3134 - Micro Load Cell (0-20 kg) - CZL635) with a linear ultrasound probe of $8 \mathrm{MHz}$ central frequency (SuperSonic Imaging, SuperLinear ${ }^{\mathrm{TM}}$ SL 15-4). Force data were acquired from the amplifier (Sparkfun, SEN-13879) of the force sensor using an Arduino card (Arduino, UNO REV 2 V4.0). US videos were acquired throughout the loading and unloading phases from a commercial device (Aixplorer, SuperSonic Imagine, France).

\subsubsection{Acquisitions}

The experimental protocol consisted in the indentation of the soft tissues of the thigh, with the setup described above, in two different configurations. In the reference configuration (R), the subject was lying and had to maintain his/her muscles relaxed (Fig. 1a). For the second configuration (C), in order to account for the impact of muscle activation on the passive mechanical response, subjects were asked to extend their knee above the void (Fig. 1b). Subjects were instructed to keep their leg straight horizontal during a complete acquisition, with a break time between each acquisition.

In order to assess the intra and inter-operator variability, two operators carried out three separated acquisitions of ten loading/unloading cycles for both configurations. The first operator had a few months of experience with US imaging and was considered an expert while the second operator never practiced US imaging and was considered as a novice user. Recommendations on the optimal speed of manual indentation and on the orientation of the probe were provided to the novice operator. Ten cycles of indentation had to last $60 \mathrm{~s}$; special attention had to be paid to avoid sliding of the probe on the tissues so that the indentation site remained the same during the experiment. One training session was carried out prior to the measurement sessions. The probe was 
positioned approximately on the mid-thigh on the anterior-lateral section and had to remain perpendicular to the bone as possible based on the US images. The first five cycles were performed to make sure that soft tissues were properly preconditioned before acquiring data.

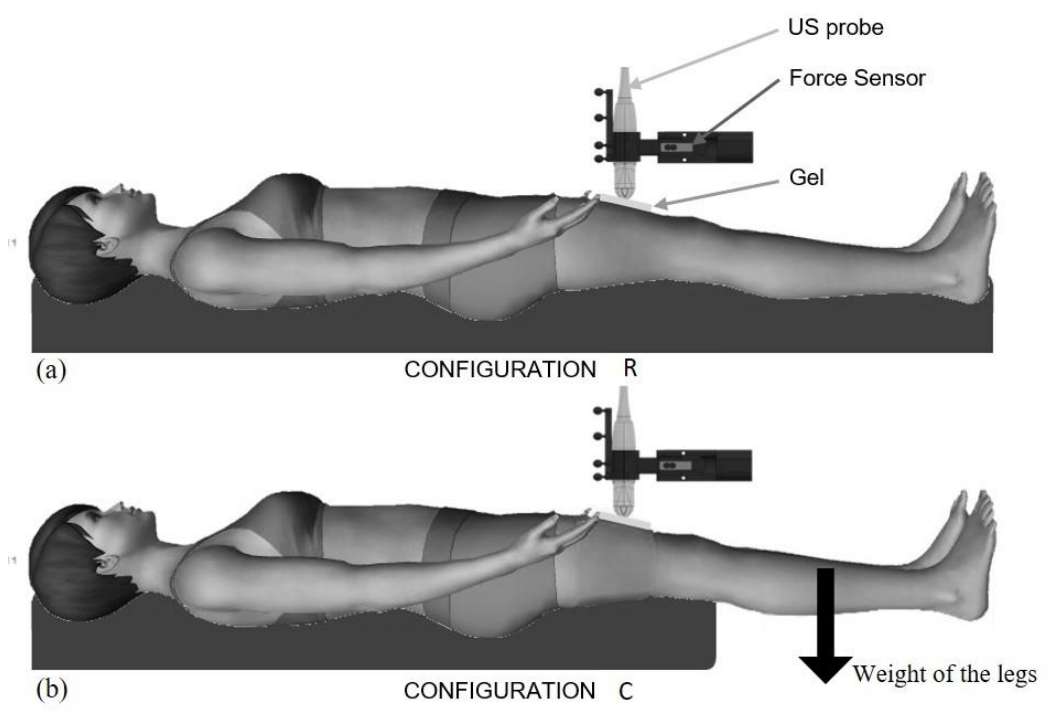

Figure 1: 1a. Configuration $\mathrm{R}$, the subject is in a relax state and compressions are applied on the anterior mid-thigh. The experimental setup composed of the US probe and the force sensor is described in this figure. $1 \mathrm{~b}$. Configuration $\mathrm{C}$, the legs of the subject are not lying on the bed, so that anterior muscles of the thigh are contracted.

\subsection{Experimental data post-processing}

Data were post-processed using Matlab (MATLAB R2014b The MathWorks, Inc., Natick, Massachusetts, United States).

First, for each operator, configuration and cycle, the position of the femur with respect to the probe was extracted semi-automatically from the US images to define the indentation displacement of the probe as follows: in the first frame, a Region Of Interest (ROI) was manually defined containing the bone contour (Fig. 2b). In each subsequent video frames, this region of interest was then tracked automatically using an adjustable threshold on image intensity. In each frame, the position of the femur was defined as the minimal vertical distance between the bone contour and the probe. The soft tissue thickness was then computed as follows: in the first frame, for which the probe was not directly in contact with the skin due to the presence of an intermediate layer of gel (Fig. 2a), the distance between the probe and the femur corresponded to the initial thickness of soft tissues. For both configurations, the average value of six thickness measurements performed by two operators (three measurements 
each) was computed and used as the estimated initial soft tissues thickness. Data for all the subjects have been referenced in Tab. 1. Similarly, for each configuration, the muscle/adipose tissue thickness ratio was computed. Displacement of soft tissues was calculated from the bone contour position on each frame to which the mean initial thickness of the corresponding configuration was subtracted.

Force and displacement data were paired based on the detection of the peak values in each of the two datasets (Fig. 3c). The force-displacement curves were derived for each loading phase. Only the five last curves of each cycle were kept for investigation of the material properties since preconditioning of soft tissues was assumed to occur during the first indentations [25]. Aberrant curves due to sliding of the probe (noticed during the indentation process) and miscomputation of the displacement during US video processing were manually removed. For both configurations and operators, the Root Mean Square Error (RMSE) between minimal and maximal curves was calculated to evaluate the intra-operator variability.

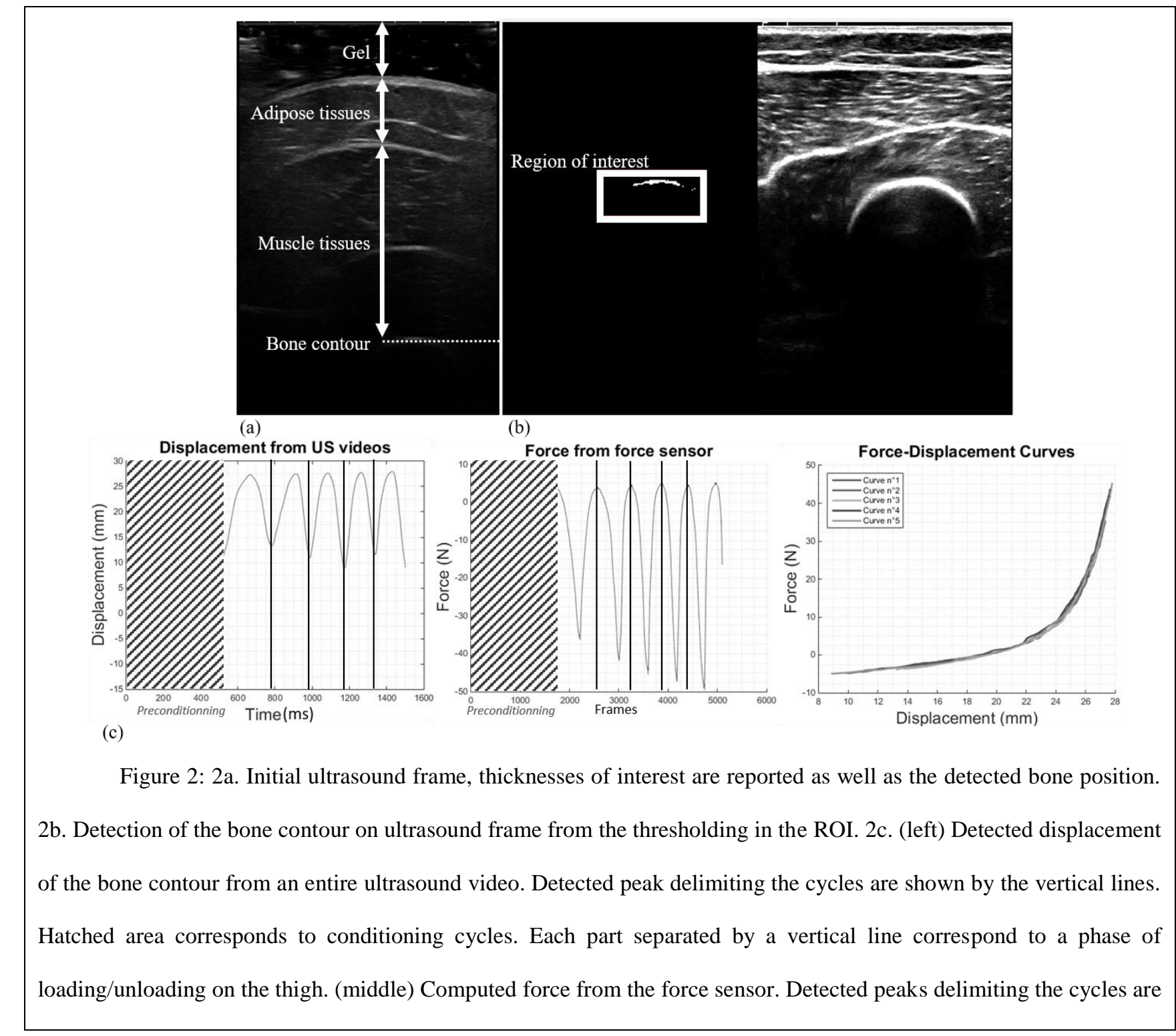


shown by vertical lines. (bottom) Computed force displacement curves from peak detection of displacement and force curves. Corresponding cycles with displacement cycles are used to compute loading force-displacement curves.

\subsection{Finite Element modelling}

\subsubsection{Geometry and meshing}

The authors designed two 3D-FE models for each subject using ABAQUS FE Analysis software (ABAQUS Inc., Providence, RI, USA), one for each configuration with the aim of identifying the personalised material properties of the soft tissues of the thigh from the experimental data described above.

In both FE models, the indenting extremity of the probe was modelled using the CAD files provided by the manufacturer. Only the lowest part of the probe, which corresponds to the part in contact with the soft tissues, was exported from the CAD file. The geometry of the other part of the probe was simplified as one bloc. The length on the indenting zone was $55 \mathrm{~mm}$.

The geometry of the two FE models of the thigh were hollow cylinders with a circular cross section. The length of the cylinders was set to three times the width of the US probe to prevent edge effects. The hole in the middle represents the femur boundary and was defined as a cylinder of generic dimensions (major axis $37 \mathrm{~mm}$ and minor axis $31 \mathrm{~mm}$ ) with an elliptical basis concentric with the external envelope cylinder. In this work, the soft tissues were modelled as one homogenous material. The initial soft tissue thickness, summarised in Tab. 1, was computed as the distance between the indentation site on the external envelope of the thigh and the contour of the bone. This defined the minimal distance between the external envelope and the bone cylinders. In anticipation of symmetries present in both the geometry and boundary conditions during the indentation phase, two planes of symmetry were considered to speed up the computation time. In configuration $\mathrm{C}$, the initial soft tissue thickness changes.

The geometry was discretised with linear hexahedral elements with hybrid formulation (C8DH), with an edge size comprised between 4 and $12 \mathrm{~mm}$. Mesh sensitivity testing demonstrated that refining the mesh produced no changes in force-displacement response, and, as a result, the initial element sizing was retained for all further analyses. Numbers of elements for each subject are detailed in Tab. 1.

The resolution was performed using an implicit scheme. The default convergence criteria in ABAQUS/Standard were used.

\subsubsection{Boundary Conditions}


Nodes of the soft tissues in contact with the femur boundary were fixed with zero degrees of freedom. The probe was defined as a rigid surface. The contact between the probe and the external envelope was modelled using as the default frictionless contact model. This is consistent with the fact that gel was applied on the skin surface during acquisitions. Soft tissues were assumed to be tied to the bone boundary. A displacement of $25 \mathrm{~mm}$ was imposed to the probe in the radial direction.

\subsubsection{Constitutive equations and identification of material parameters}

Soft tissues were assumed to exhibit a hyper-elastic behaviour and were modelled using an Ogden nonlinear constitutive law [43] Eq. (1) :

(1) $U=\frac{2 \mu}{\alpha^{2}}\left(\bar{\lambda}_{1}^{\alpha}+\bar{\lambda}_{2}^{\alpha}+\bar{\lambda}_{3}^{\alpha}-3\right)+\frac{1}{D_{i}}\left(J^{e l}-1\right)^{2 i}$

With $\mathrm{U}$ the strain energy potential, $\bar{\lambda}_{i}$ the deviatoric principal stretches, $\mathrm{J}^{\mathrm{el}}$ the elastic volume ratio, $\mu$ the shear modulus and $D$ the incompressibility parameter and $\alpha$ the exponent. The material parameters, $\mu$ and $\alpha$, of the constitutive law were calibrated against experimental curves in a custom-made MATLAB routine described in the section hereafter. The parameter D, was set according the value of the shear modulus using the formula developed in [44] with a Poisson's ratio of 0.49 since soft tissues are considered as nearly incompressible Eq. (2). Parameter $\kappa$ is the bulk modulus and $v$ the Poisson's ratio.

(2) $D=\frac{2}{\kappa} \approx \frac{3(1-2 v)}{\mu(1+v)}$

Values of material parameters were optimised using the fmincon built-in function in MATLAB. A constraint was added so that the product of the shear modulus and the exponent parameter was always positive [45]. The cost function was defined as the RMSE between experimental and simulated curves. Since intra-subject variability was low, the optimisation was only computed on the mean curve of each configuration and each operator of all subjects. Simulated curves were constructed with the displacement of soft tissues and the reaction force applied on the probe. The simulated displacement of the soft tissues ensued form the displacement of the reference point of the probe. The simulated reaction force computed on the surface of the probe, multiplied by four due to the two symmetries, was used to compute the force applied on soft tissues. Initial parameters values for the optimisation are $1 \mathrm{kPa}$ and 30, respectively for $\mu$ and $\alpha$, for configuration $\mathrm{R}$, and $10 \mathrm{kPa}$ and 5 for configuration C.

\subsection{Statistical Analysis}


Statistical analysis was performed on values of both $\mu$ and $\alpha$ parameters with 2-way repeated ANOVA tests in order to investigate the impact of the configuration and the operator on the mechanical response of soft tissues. 


\section{Results}

\subsection{Experimental curves}

The experimental force-displacement curves of the subjects are presented for both configurations and for the two operators on Fig. 3a and 3b. The distinction of the two configurations is clear regardless of the operator.

The mean responses of all subjects corresponding to each configuration are given for one operators in Fig. 4. The maximal RMSE between minimal and maximal curves for the first operator is $9.3 \mathrm{~N}$ for configuration $\mathrm{R}$ and $12.3 \mathrm{~N}$ for configuration $\mathrm{C}$. Concerning, the second operator the maximal RMSE is about $9.1 \mathrm{~N}$ for both configurations.

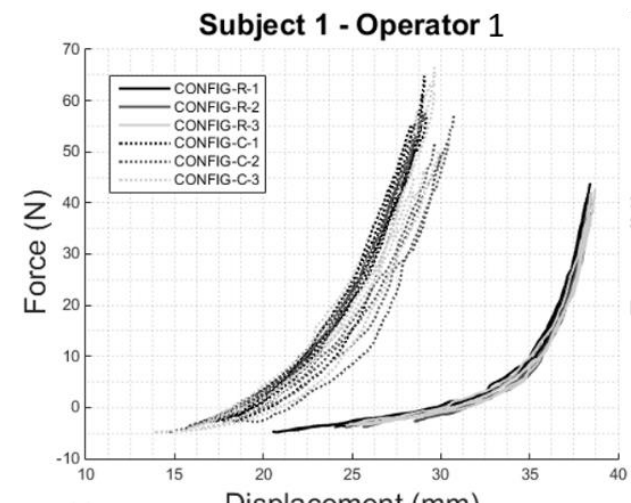

(a)

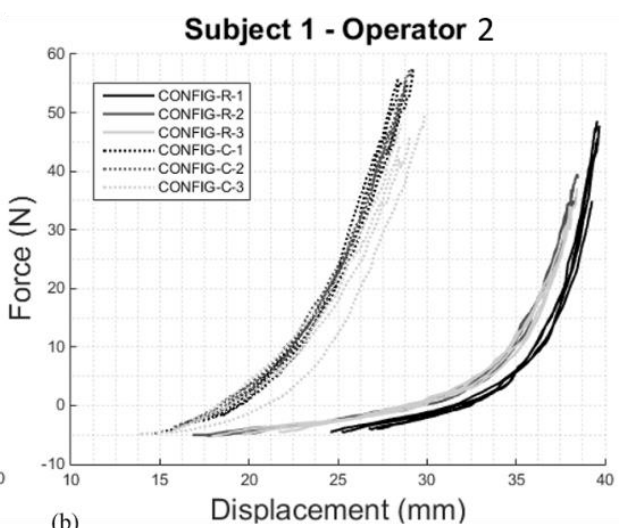

(b)

Figure 3: 3a. Experimental force-displacement curves obtained by operator 1 for one subject. The two colours correspond to the two cycles of indentation. 3b. Experimental force-displacement curves obtained by operator 2 for one subject. The two colours correspond to the two cycles of indentation.

\subsection{Identification of constitutive parameters}

Experimental and simulated curves are presented on Fig. 4 for all subjects and for one operator in the two configurations. The CPU time for the identification of the material properties for each curve was about $30 \mathrm{~min}$. Final mean RMSE was 6.1 N. Identified values of shear modulus, $\alpha$ and tissues thickness, and ratio are detailed in

Tab. 1. The mean shear modulus determined with the first operator experimental curves is $3.3 \pm 1.3,13.0 \pm 6.0$ $\mathrm{kPa}$ for configurations $\mathrm{R}$ and $\mathrm{C}$ respectively. Mean $\alpha$ is $10 \pm 1,9 \pm 4$ respectively for configurations $\mathrm{R}$ and $\mathrm{C}$. Measurements made by the second operator provided the following values of shear modulus: $3.0 \pm 1.3,14.3 \pm 7.2$ 
$\mathrm{kPa}$ and for $\alpha: 10 \pm 1,9 \pm 3$. Comparison of force-displacement curves from the simulation and from the experimental measurements is depicted in Fig. 4. The results of the FEA are presented for one subject in Fig. 5.

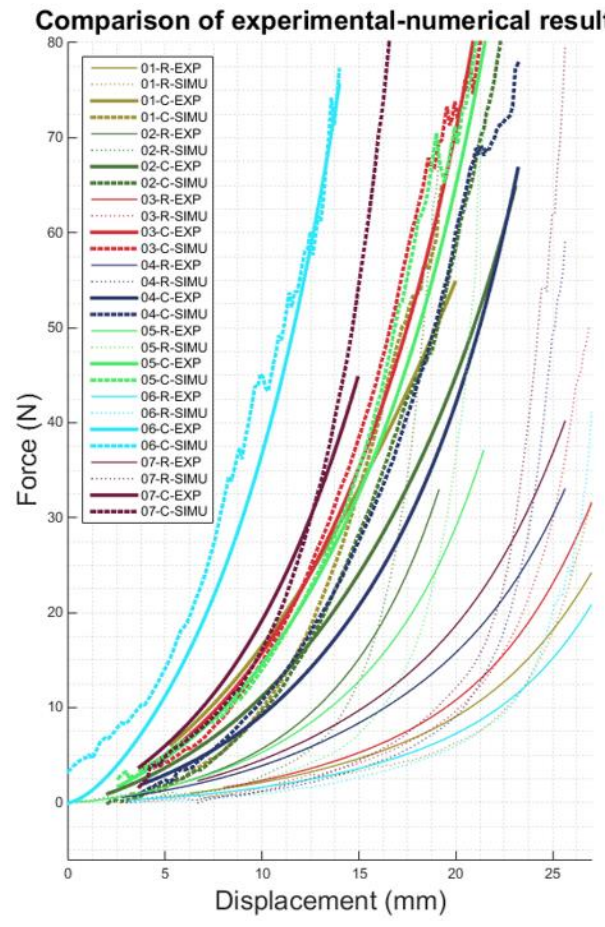

Figure 4: Comparison of experimental and numerical force-displacement curves for all subjects with one operator in both configurations. Thin lines represent configuration $\mathrm{R}$, wide lines represent configuration $\mathrm{C}$. Experimental curves are represented in continuous lines and numerical curves in dotted lines.

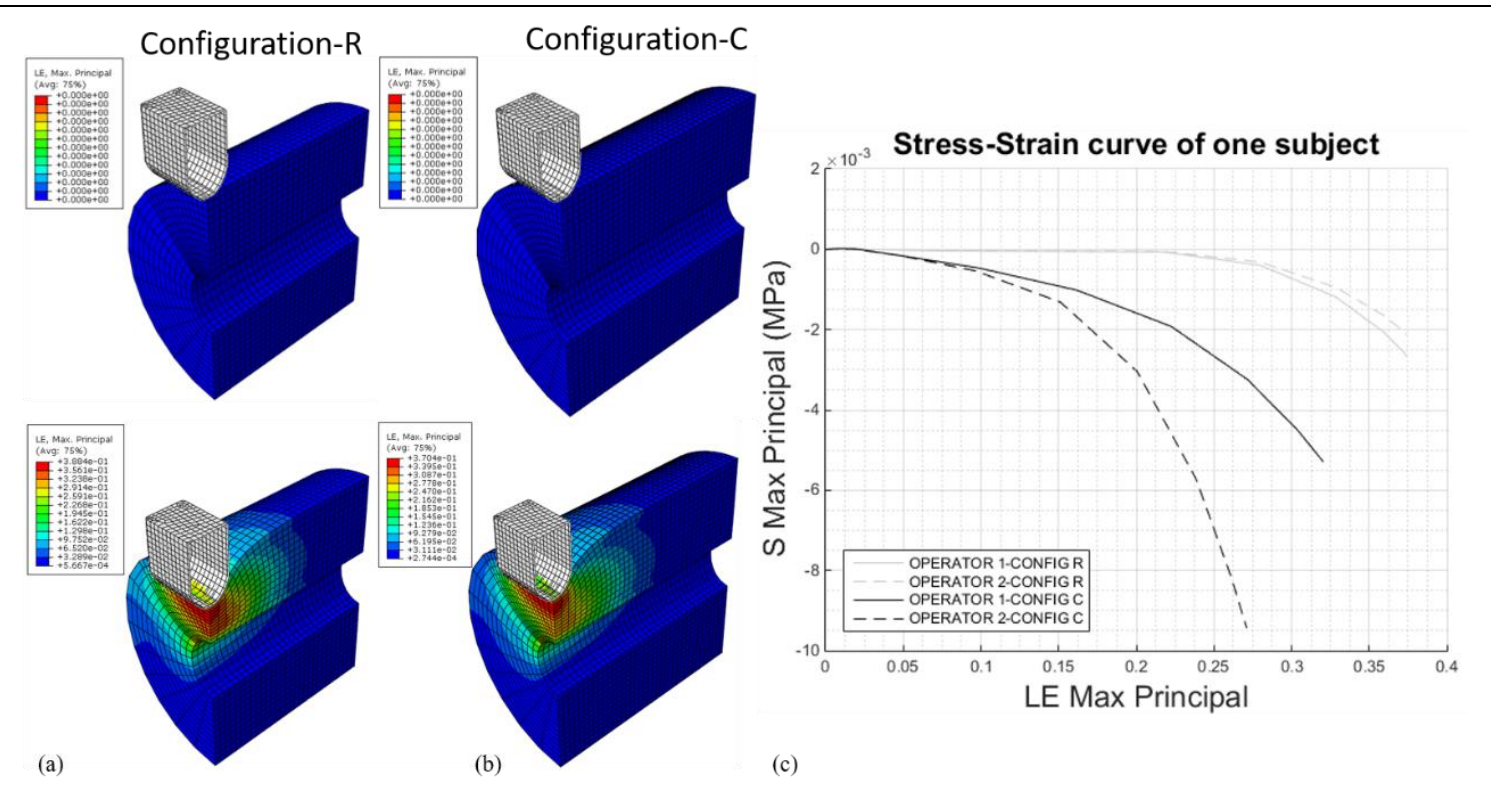

Figure 5: Typical mechanical response in both the muscle relaxed (R) and muscle contracted (C) configurations (for subject \#5): 5a. muscle relaxed (R) configuration (top) initial undeformed state and (bottom) distribution of the maximal principal logarithmic strain predicted by the FE model $5 \mathrm{~b}$. muscle contracted $(\mathrm{C})$ configuration (top) initial undeformed state and (bottom) distribution of the maximal principal logarithmic strain predicted by the FE model 5c. Plot of the maximum principal stress as a function of the maximal principal 
logarithmic strain for one subject, for both operators and for both configurations in the element at mid-distance between the probe and the femur.

\begin{tabular}{|c|c|c|c|c|c|c|c|c|c|c|c|}
\hline \multirow{3}{*}{$\begin{array}{l}\stackrel{n}{0} \\
. \frac{0}{0} \\
\bar{\Xi} \\
0\end{array}$} & \multirow[t]{3}{*}{ BMI } & \multirow[t]{3}{*}{ Configurations } & \multirow{3}{*}{$\begin{array}{l}\text { Mean } \\
\text { initial } \\
\text { thickness } \\
(\mathrm{mm})\end{array}$} & \multicolumn{2}{|c|}{ Initial parameters } & \multicolumn{4}{|c|}{ Optimised parameters } & \multirow{3}{*}{$\begin{array}{l}\text { Adipose } \\
\text { thickness / } \\
\text { Muscle } \\
\text { thickness }\end{array}$} & \multirow{3}{*}{$\begin{array}{l}N^{\circ} \text { of } \\
\text { elements }\end{array}$} \\
\hline & & & & & & \multicolumn{2}{|c|}{ Operator $1(\mathrm{DH})$} & \multicolumn{2}{|c|}{ Operator 2 (NF) } & & \\
\hline & & & & $\mathrm{MU}(\mathrm{kPa})$ & ALPHA & $\mathrm{MU}(\mathrm{kPa})$ & ALPHA & $\mathrm{MU}(\mathrm{kPa})$ & ALPHA & & \\
\hline \multirow[t]{2}{*}{1} & \multirow[t]{2}{*}{21.4} & $\mathrm{R}$ & 52.0 & 2 & 10 & 1.75 & 10 & 1.86 & 10 & 0.36 & 8970 \\
\hline & & $\mathrm{C}$ & 52.5 & 12 & 5 & 13.19 & 2 & 13.98 & 3 & 0.31 & 11362 \\
\hline \multirow[t]{2}{*}{2} & \multirow[t]{2}{*}{21.8} & $\mathrm{R}$ & 40.6 & 2 & 10 & 4.24 & 11 & 4.33 & 11 & 0.23 & 6000 \\
\hline & & $\mathrm{C}$ & 49.4 & 12 & 5 & 9.95 & 5 & 9.25 & 7 & 0.18 & 10032 \\
\hline \multirow[t]{2}{*}{3} & \multirow[t]{2}{*}{21.8} & $\mathrm{R}$ & 49.9 & 2 & 10 & 2.00 & 10 & 2.00 & 10 & 0.27 & 7920 \\
\hline & & $\mathrm{C}$ & 51.4 & 12 & 5 & 8.48 & 10 & 12.88 & 10 & 0.19 & 11362 \\
\hline \multirow[t]{2}{*}{4} & \multirow[t]{2}{*}{21.7} & $\mathrm{R}$ & 49.4 & 2 & 10 & 4.30 & 8 & 3.43 & 8 & 0.15 & 7920 \\
\hline & & $\mathrm{C}$ & 56.0 & 12 & 5 & 9.95 & 7 & 7.31 & 12 & 0.13 & 12768 \\
\hline \multirow[t]{2}{*}{5} & \multirow[t]{2}{*}{22.3} & $\mathrm{R}$ & 46.1 & 2 & 10 & 4.68 & 11 & 4.31 & 11 & 0.15 & 7260 \\
\hline & & $\mathrm{C}$ & 52.0 & 12 & 5 & 8.90 & 13 & 11.93 & 10 & 0.14 & 11362 \\
\hline \multirow[t]{2}{*}{6} & \multirow[t]{2}{*}{23.8} & $\mathrm{R}$ & 43.5 & 2 & 10 & 1.94 & 10 & 1.36 & 8 & 0.13 & 6930 \\
\hline & & $\mathrm{C}$ & 43.5 & 12 & 5 & 25.5 & 12 & 29.36 & 10 & 0.12 & 8360 \\
\hline \multirow[t]{2}{*}{7} & \multirow[t]{2}{*}{24.3} & $\mathrm{R}$ & 50.8 & 2 & 10 & 3.86 & 10 & 3.91 & 9 & 0.34 & 8970 \\
\hline & & $\mathrm{C}$ & 50.8 & 12 & 5 & 14.72 & 11 & 15.33 & 12 & 0.34 & 11362 \\
\hline
\end{tabular}

Table 1: Clinical data of all subjects and results of the optimisation process on the constitutive parameters of the thigh in both configuration for each operator

\subsection{Relative effect of structural parameters}

The results of the ANOVA test show that the influence of the operator is not significant $\left(\mathrm{p}_{\mu}=0.32\right.$ and $\mathrm{p}_{\alpha}$ $=0.90)$. The exponent parameter, $\alpha$, was also not significantly impacted by the configuration $\left(\mathrm{p}_{\alpha}=0.54\right)$. On the contrary, the estimated value of the shear modulus was significantly influenced by the configuration $\left(\mathrm{p}_{\mu}<0.01\right)$. 


\section{Discussion}

The current study presents a method to combine inverse FEM and freehand ultrasound-based indentation for the identification of the passive material properties of the soft tissues of the thigh. Factually, most of the studies dealing with FEM of the thigh do not personalise the material properties of soft tissues, and would rather turn to values from literature $[1,6-8,10]$. Indeed, very few studies developed the necessary process to estimate the personalised mechanical behaviour of soft tissues, especially when large soft tissues thicknesses are involved, like in the thigh area. As an alternative, in the present study, a FE model was designed to simulate the experiment and predict material properties of soft tissues using an Ogden constitutive law.

In addition, the procedure introduced in this paper was designed in order to simplify and hasten the computation of the non-linear parameters of the thigh by using a freehand US setup. The freehand US setup and the simplified FE model allow to align with the clinical routine constraints in terms of simplicity, time of acquisition and segmentation, time of computation, and cost of necessary devices. A previous study conducted on the forearm of several subjects, has already highlighted the feasibility to assess the mechanical behaviour of the soft tissues from freehand US in a repeatable manner in this area [46]. In the present study, the identification of material parameters of the thigh from a similar experimental procedure was shown to be robust even for novice users of US apparatus. Indeed, two operators, with a different level of expertise, repeated the measurements several times. The inter-operator variability was low and differences among operators were not significant $\left(\mathrm{p}_{\mu}>0.1\right.$ and $\mathrm{p}_{\alpha}>0.5$ ) according to the results of the 2-way repeated ANOVA test. On the contrary, the mechanical behaviour of soft tissues was significantly affected by a change in muscle contraction $\left(\mathrm{p}_{\mu}<0.01\right)$. This is consistent with the results of studies performed on the lower leg by Mak et al. [25,26]. In other words, these results emphasize the non-negligible relative influence of muscles activity on constitutive parameters of soft tissues. Therefore, when studying the interaction of the lower limb with a medical device, such as a prosthesis or exoskeleton, the mode of use of the medical device (i.e. active or passive) should be distinguished when personalising the constitutive law of soft tissues. The material properties of the soft tissues of the thigh may be considered as subject-specific according the inter-subject variability (In average for configuration R: $\alpha=10 \pm 1$ and $\mu=3.2 \pm 1.3 \mathrm{kPa}$, in average for configuration $\mathrm{C}: \alpha=9 \pm 3$ and $\mu=13.7 \pm 6.5 \mathrm{kPa}$ ). One limitation lies in the composition of the sample that includes only asymptomatic participants with similar BMI $\left(22.4 \pm 1.1 \mathrm{~cm} \cdot \mathrm{kg}^{-2}\right)$, which does not represent the heterogeneity of the structural composition of the thigh. However, the adipose over muscle tissue ratio, computed in configuration $\mathrm{R}$, was $0.23 \pm 0.09$ meaning that the muscular volumes and/or the adipose rates were different 
among subjects. Further investigations, on disabled or pathological subjects could support the presented conclusions.

Direct comparisons of the values of the material parameters with literature is complicated by the wide variability of possible constitutive laws to model the soft tissues behaviour. In the presented study, a first order, non-linear, hyperelastic Ogden model was implemented, and the shear modulus, $\mu$, and the exponent parameter, $\alpha$, were estimated to fit the behaviour observed experimentally. In order to compare the values, estimated shear modulus was computed either from the Young's modulus or the Mooney-Rivlin parameters [47]. However, the comparison could also be intricate due to differences in areas of indentation. Reported values of material parameters of the thigh soft tissues in the literature were equivalent to a shear modulus comprised between $1 \mathrm{kPa}$ and $46 \mathrm{kPa}$ and no values were reported concerning the exponent parameter [17,18,39]. As far as the authors are aware of, Affagard et al. were the only ones to performed inverse FE modelling on the thigh [17]. They performed compression tests using two plates above and under the distal part of the thigh of one subject. One of the plates was instrumented with an ultrasound probe to record displacement data of the soft tissues in order to compute a digital image correlation. Soft tissues were modelled with a Neo-Hookean constitutive law for both adipose and muscular tissues modelled separately. Estimations of shear moduli were about $1 \mathrm{kPa}$ and $23 \mathrm{kPa}$ for adipose and muscular tissues respectively. Geometry of the thigh for the finite element model was obtained from MRI acquisitions in order to distinguish fat and muscles. It must be noticed that imaging systems, such as MRI, are not accessible to prosthetists for example, and require long segmentation time. On the contrary, in the present study, only US imaging was employed and thus soft tissues were fused in one entity. For comparison purpose, analytical identifications of fused soft tissues material parameters of the thigh are also detailed afterwards. In particular, Sadler et al. estimated material parameters of the posterior thigh tissues from experimental force-deflection data at three levels: distal, proximal and middle thigh [18]. Subjects were asked to sit on a chair instrumented with an indenter and a load cell. Soft tissues were modelled with a Mooney-Rivlin non-linear constitutive law for which stress and strain were computed from the force-deflection data. The computation of the strain from the deflection was performed thanks to a correlation study conducted on literature values, from cadaver experiments. A curvefitting method was used to optimise values of the Mooney-Rivlin mechanical parameters and reported equivalent shear moduli comprised between $7 \mathrm{kPa}$ and $46 \mathrm{kPa}$ for the three areas. In another way, Krouskop et al. computed the Young's modulus of one subject's lateral thigh at $10 \%$ strain from US Doppler indentations [39]. These authors did not designed an inverse FE process to estimate the Young's modulus but computed it from an analytical formula. The equivalent shear modulus was about $2 \mathrm{kPa}$. In a nutshell, the mean shear modulus of $3 \mathrm{kPa}$ estimated 
in the present study for the relaxed configuration $\mathrm{R}$ is in the lower range of values reported in the literature but values are tedious to compare. Indeed, identified parameters were different from one study to another and thus, one may only compute an equivalent shear modulus for comparison purpose and variations in the exponent parameter, $\alpha$, cannot be considered. Sites of indentation, process of resolution (analytical or inverse FE modelling) and FE model geometry also obviously influence the results.

Very few data are available in the existing literature for the contracted muscle configuration even though this is a major concern when dealing with the daily use of medical device. In configuration C, muscles are contracted as it may occur during walking activities with prosthesis. Krouskop et al. studied the influence of muscle mass contraction at two levels at a 10\% tissue strain level [39]. The subject had to support a weight about $2.3 \mathrm{~kg}$ for the first level of contraction and to develop their maximal force at the second level. Reported equivalent shear moduli were about $12 \mathrm{kPa}$ and $37 \mathrm{kPa}$ for both levels of contraction respectively. These results are consistent with the ones presented in this study where the mean shear modulus of the contracted state is around $13 \mathrm{kPa}$. The muscular contraction force was not measured in both studies, which is justified by the aim of simplifying the experimental process. Quantifying this force could be done by isometric contraction in a future version of the protocol.

In addition, various aspects of the presented method may influence the values of constitutive parameters of the soft tissues. On one hand, concerning the experimental acquisitions, several indentation parameters were not controlled in order to have a freehand setup. The speed of indentation, the orientation and the position of the probe were not fixed even though operators had to follow some instructions: probe perpendicular to the bone, area of indentation, and number of cycles per videos. Still, these parameters could affect the results [48] as the speed of indentation was shown to impact the response of biological tissues $[29,49]$. In addition, the indentation axis was not coincident with the bone due to the medial position of the femur in the thigh. This error is inherent to a freehand process of indentation. Although operators had the consign to position the probe and remain above the bone, the probe could slightly slide. However, this sliding did not induce high variations in force-displacement curves and thus, although visible on the US images, this off-axis was not considered in the FE model. On the other hand, the FE model may not quantify the real mechanical behaviour of the soft tissues under compression loadings but only equivalent constitutive parameters. Indeed, the hypotheses made to compute material properties with an acceptable level of complexity concern the soft tissues that were fused together, boundary conditions, lying support, real geometry of tissues, and sliding. Another limitation that could be tackled as a perspective is the assumption that the viscoelasticity of the material can be neglected. Indeed, viscoelasticity may appear while using a 
medical device in extended posture bearing and could be the focus of another study. However, the developed protocol is still consistent with the overall goal of this study. Authors were able to identify the material properties of soft tissues of the thigh for FEM of the interaction with a medical device from a process accessible in clinics.

One of the main challenges facing the biomechanical community today is the translation of FE models from academic research laboratories into a framework compatible with clinical routine in order to be clinically relevant. However, FEM brings new insights into the design of external medical devices, such as prosthesis, for example by computing a map of external pressures applied on the residual limb. Amongst the major obstacles that need to be addressed, the identification of the in vivo constitutive parameters of the biological soft tissues that describe the material properties is fundamental. Building upon new and unique opportunities offered by US imaging, the aim of the current study was to highlight the feasibility of combining inverse FEM and freehand USbased indentation for the identification of the passive material properties of soft tissues of the thigh. As a perspective, these values could be used as input data for modelling the soft tissues in a FE model to predict contact interactions between a body part and a medical device in case of both passive and active uses. 


\section{Acknowledgement}

The authors are also grateful to the ParisTech BiomecAM chair program on subject-specific musculoskeletal modelling (with the support of ParisTech and Yves Cotrel Foundations, Société Générale, Proteor and Covea) and to Proteor for their financial support.

\section{Conflict of interest}

The authors certify that no conflict of interest is raised by this work.

\section{References}

[1] G. Colombo, R. Morotti, C. Rizzi, FE Analysis of Contact between Residual Limb and Socket during Simulation of Amputee Motion, Comput. Aided. Des. Appl. 11 (2014) 381-388. doi:10.1080/16864360.2014.881178.

[2] D.M. Sengeh, K.M. Moerman, A. Petron, H. Herr, Multi-material 3-D viscoelastic model of a transtibial residuum from in-vivo indentation and MRI data, J. Mech. Behav. Biomed. Mater. 59 (2016) 379-392. doi:10.1016/j.jmbbm.2016.02.020.

[3] X. Jia, M. Zhang, X. Li, W.C.C. Lee, A quasi-dynamic nonlinear finite element model to investigate prosthetic interface stresses during walking for trans-tibial amputees, Clin. Biomech. 20 (2005) 630-635. doi:10.1016/j.clinbiomech.2005.03.001.

[4] W.C.C. Lee, M. Zhang, X. Jia, J.T.M. Cheung, Finite element modelling of the contact interface between trans-tibial residual limb and prosthetic socket, Med. Eng. Phys. (2004). doi:10.1016/j.medengphy.2004.04.010.

[5] M. Zhang, C. Roberts, Comparison of computational analysis with clinical measurement of stresses on below-knee residual limb in a prosthetic socket, Med. Eng. Phys. 22 (2000) 607-612. doi:10.1016/S1350-4533(00)00079-5.

[6] G. Colombo, C. Comotti, D.F. Redaelli, D. Regazzoni, C. Rizzi, A. Vitali, A method to improve prosthesis leg design based on pressure analysis at the socket-residual limb interface, Proc. ASME Des. Eng. Tech. Conf. 1A-2016 (2016) 1-8. doi:10.1115/DETC2016-60131.

[7] M. Zhang, A.F.T. Mak, A finite element analysis of the load transfer between an above-knee residual limb and its prosthetic socket - Roles of interface friction and distal-end boundary conditions, IEEE Trans. Rehabil. Eng. (1996). doi:10.1109/86.547935.

[8] D. Lacroix, J.F.R. Patiño, Finite element analysis of donning procedure of a prosthetic transfemoral socket, Ann. Biomed. Eng. (2011). doi:10.1007/s10439-011-0389-z.

[9] J. Andrés Vélez Zea, L. Marcela, B. Góez, J. Abdul, V. Ossa, Relation Between Residual Limb Length and Stress Distribution over Stump for Transfemoral Amputees, (n.d.). doi:10.14508/reia.2015.12.23.107-115.

[10] J.F. Ramírez, J.A. Vélez, Incidence of the boundary condition between bone and soft tissue in a finite element model of a transfemoral amputee, Prosthet. Orthot. Int. 36 (2012) 405-414. doi:10.1177/0309364612436409.

[11] G. Colombo, S. Filippi, C. Rizzi, F. Rotini, A new design paradigm for the development of custom-fit soft sockets for lower limb prostheses, Comput. Ind. 61 (2010) 513-523. doi:10.1016/j.compind.2010.03.008.

[12] V. Restrepo, J. Villarraga, J.P. Palacio, Stress reduction in the residual limb of a transfemoral amputee varying the coefficient of friction, J. Prosthetics Orthot. 26 (2014) 205-211. doi:10.1097/JPO.0000000000000044.

[13] E. Ramasamy, O. Avci, B. Dorow, S.-Y. Chong, L. Gizzi, G. Steidle, F. Schick, O. Röhrle, An Efficient Modelling-Simulation-Analysis Workflow to Investigate Stump-Socket Interaction Using PatientSpecific, Three-Dimensional, Continuum-Mechanical, Finite Element Residual Limb Models, Front. Bioeng. Biotechnol. 6 (2018) 1-17. doi:10.3389/fbioe.2018.00126. 
[14] J.T.M. Cheung, M. Zhang, A.K.L. Leung, Y.B. Fan, Three-dimensional finite element analysis of the foot during standing - A material sensitivity study, J. Biomech. 38 (2005) 1045-1054. doi:10.1016/j.jbiomech.2004.05.035.

[15] A.S. Dickinson, J.W. Steer, P.R. Worsley, Finite element analysis of the amputated lower limb: A systematic review and recommendations, Med. Eng. Phys. 43 (2017) 1-18. doi:10.1016/j.medengphy.2017.02.008.

[16] J.-S. Affagard, S.F. Bensamoun, P. Feissel, Development of an Inverse Approach for the Characterization of In Vivo Mechanical Properties of the Lower Limb Muscles, J. Biomech. Eng. 136 (2014) 111012. doi:10.1115/1.4028490.

[17] J.S. Affagard, P. Feissel, S.F. Bensamoun, Identification of hyperelastic properties of passive thigh muscle under compression with an inverse method from a displacement field measurement, J. Biomech. 48 (2015) 4081-4086. doi:10.1016/j.jbiomech.2015.10.007.

[18] Z. Sadler, J. Scott, J. Drost, S. Chen, S. Roccabianca, T.R. Bush, Initial estimation of the in vivo material properties of the seated human buttocks and thighs, Int. J. Non. Linear. Mech. 107 (2018) 77-85. doi:10.1016/j.ijnonlinmec.2018.09.007.

[19] A.P. Pathak, M.B. Silver-Thorn, C.A. Thierfelder, T.E. Prieto, A rate-controlled indentor for in vivo analysis of residual limb tissues, IEEE Trans. Rehabil. Eng. 6 (1998) 12-20. doi:10.1109/86.662616.

[20] Y.P. Zheng, A.F.T. Mak, Extraction of Quasi-Linear Viscoelastic Parameters for Lower Limb Soft Tissues From Manual Indentation Experiment, J. Biomech. Eng. 121 (1999) 330. doi:10.1115/1.2798329.

[21] K.M. Moerman, A.M.J. Sprengers, A.J. Nederveen, C.K. Simms, A novel MRI compatible soft tissue indentor and fibre Bragg grating force sensor, Med. Eng. Phys. 35 (2013) 486-499. doi:10.1016/j.medengphy.2012.06.014.

[22] M.A.L. Bell, S. Kumar, L. Kuo, H.T. Sen, I. Iordachita, P. Kazanzides, Toward Standardized Acoustic Radiation Force (ARF)-Based Ultrasound Elasticity Measurements with Robotic Force Control, IEEE Trans. Biomed. Eng. 63 (2016) 1517-1524. doi:10.1109/TBME.2015.2497245.

[23] M. Malinauskas, T.A. Krouskop, P.A. Barry, Noninvasive measurement of the stiffness of tissue in the above-knee amputation limb, J. Rehabil. Res. Dev. 26 (1989) 45-52.

[24] J.C. Goh, P.V.S. Lee, S.L. Toh, C.K. Ooi, Development of an integrated CAD-FEA process for belowknee prosthetic sockets, Clin. Biomech. 20 (2005) 623-629. doi:10.1016/j.clinbiomech.2005.02.005.

[25] Y.P. Zheng, A.F.T. Mak, Effective elastic properties for lower limb soft tissues from manual indentation experiment, IEEE Trans. Rehabil. Eng. 7 (1999) 257-267. doi:10.1109/86.788463.

[26] A.F.T. Mak, G.H. Liu, S.Y. Lee, Biomechanical assessment of below-knee residual limb tissue, J. Rehabil. Res. Dev. 31 (1994) 188-198.

[27] W.C. Hayes, L.M. Keer, G. Herrmann, L.F. Mockros, A mathematical analysis for indentation tests of articular cartilage, J. Biomech. 5 (1972) 541-551. doi:10.1016/0021-9290(72)90010-3.

[28] M. Zhang, Y.P. Zheng, A.F.T. Mak, Estimating the effective Young's modulus of soft tissues from indentation tests - nonlinear finite element analysis of effects of friction and large deformation, Med. Eng. Phys. 19 (1997) 512-517. doi:10.1016/S1350-4533(97)00017-9.

[29] Y.P. Zheng, A.F.T. Mak, B. Lue, Objective assessment of limb tissue elasticity: development of a manual indentation procedure., J. Rehabil. Res. Dev. 36 (1999) 71-85.

[30] Y. Fung, Elasticity of soft tissues in simple elongation, Am. J. Physiol. Content. 213 (1967) 1532-1544. doi:10.1152/ajplegacy.1967.213.6.1532.

[31] F. Frauziols, F. Chassagne, P. Badel, L. Navarro, J. Molimard, N. Curt, S. Avril, In vivo Identification of the Passive Mechanical Properties of Deep Soft Tissues in the Human Leg, Strain. 52 (2016) 400-411. doi:10.1111/str.12204.

[32] A. Samani, D. Plewes, A method to measure the hyperelastic parameters of ex vivo breast tissue samples, Phys. Med. Biol. 49 (2004) 4395-4405. doi:10.1088/0031-9155/49/18/014.

[33] P.A.L.S. Martins, R.M.N. Jorge, A.J.M. Ferreira, A comparative study of several material models for prediction of hyperelastic properties: Application to silicone-rubber and soft tissues, Strain. 42 (2006) 135-147. doi:10.1111/j.1475-1305.2006.00257.x.

[34] V. Vavourakis, J.H. Hipwell, D.J. Hawkes, An Inverse Finite Element u/p-Formulation to Predict the Unloaded State of In Vivo Biological Soft Tissues, Ann. Biomed. Eng. 44 (2016) 187-201. doi:10.1007/s10439-015-1405-5.

[35] M. Kauer, V. Vuskovic, J. Dual, G. Szekely, M. Bajka, Inverse finite element characterization of soft tissues, Lect. Notes Comput. Sci. (Including Subser. Lect. Notes Artif. Intell. Lect. Notes Bioinformatics). 2208 (2001) 128-136. doi:10.1007/3-540-45468-3_16.

[36] M.B. Silver-Thorn, D.S. Childress, M. Rlarbara Siver®thor-, S.C. Ldress, M. Barbara Silver-Thorn, Generic, geometric finite element analysis of the transtibial residual limb and prosthetic socket, J. Rehabil. Res. Dev. 34 (1997) 171-186. 
[37] C.C. Lin, C.H. Chang, C.L. Wu, K.C. Chung, I.C. Liao, Effects of liner stiffness for trans-tibial prosthesis: A finite element contact model, Med. Eng. Phys. 26 (2004) 1-9. doi:10.1016/S13504533(03)00127-9.

[38] D.M. Sengeh, K.M. Moerman, A. Petron, H. Herr, Multi-material 3-D viscoelastic model of a transtibial residuum from in-vivo indentation and MRI data, J. Mech. Behav. Biomed. Mater. 59 (2016) 379-392. doi:10.1016/j.jmbbm.2016.02.020.

[39] T. a Krouskop, D.R. Dougherty, F.S. Vinson, A pulsed Doppler ultrasonic system for making noninvasive measurements of the mechanical properties of soft tissue., J. Rehabil. Res. Dev. 24 (1987) 1-8. doi:10.1007/BF00375720.

[40] E. Linder-Ganz, N. Shabshin, Y. Itzchak, A. Gefen, Assessment of mechanical conditions in sub-dermal tissues during sitting: A combined experimental-MRI and finite element approach, J. Biomech. 40 (2007) 1443-1454. doi:10.1016/j.jbiomech.2006.06.020.

[41] R.M.A. Al-Dirini, M.P. Reed, J. Hu, D. Thewlis, Development and Validation of a High Anatomical Fidelity FE Model for the Buttock and Thigh of a Seated Individual, Ann. Biomed. Eng. 44 (2016) 2805-2816. doi:10.1007/s10439-016-1560-3.

[42] A. Macron, H. Pillet, J. Doridam, A. Verney, P.Y. Rohan, Development and evaluation of a new methodology for the fast generation of patient-specific Finite Element models of the buttock for sittingacquired deep tissue injury prevention, J. Biomech. 79 (2018) 173-180. doi:10.1016/j.jbiomech.2018.08.001.

[43] R.W. Ogden, Large Deformation Isotropic Elasticity-On the Correlation of Theory and Experiment for Incompressible Rubberlike Solids, Rubber Chem. Technol. 46 (1972) 398-416. doi:10.5254/1.3542910.

[44] P.H. Mott, J.R. Dorgan, C.M. Roland, The bulk modulus and Poisson's ratio of "incompressible" materials, J. Sound Vib. 312 (2008) 572-575. doi:10.1016/j.jsv.2008.01.026.

[45] G. (Geoffrey) Allen, Comprehensive polymer science and supplements, [Elsevier], 1996. https://wwwsciencedirect-com.rp1.ensam.eu/referencework/9780080967011/comprehensive-polymer-science-andsupplements (accessed September 4, 2019).

[46] Y.P. Zheng, A.F.T. Mak, Extraction of Effective Young's Modulus of Skin and Subcutaneous Tissues from Manual Indentation Data, Proc. 19th Int. Conf. IEEE/EMBS. 2246 (1997) 2246-2249.

[47] G. Mavko, T. Mukerji, J. Dvorkin, The Rock Physics Handbook, 1998. doi:10.1017/S0016756899413329.

[48] A.F.T. Mak, M. Zhang, D.A. Boone, State-of-the-art methods for geometric and biomechanical assessments of residual limbs: a review., J. Rehabil. Res. Dev. 38 (2001) 161-174.

[49] E. Tönük, M.B. Silver-Thorn, E. Tönük, M.B. Silver-Thorn, E. Tönük, M.B. Silver-Thorn, Nonlinear Viscoelastic Material Property Estimation of Lower Extremity Residual Limb Tissues, IEEE Trans. Neural Syst. Rehabil. Eng. 126 (2003) 289. doi:10.1109/TNSRE.2003.810436. 


\section{List of figures}

\begin{tabular}{|c|c|}
\hline Figure 1 & $\begin{array}{l}\text { 1a. Configuration } \mathrm{R} \text {, the subject is in a relax state and compressions are applied } \\
\text { on the anterior mid-thigh. The experimental setup composed of the US probe and the } \\
\text { force sensor is described in this figure. 1b. Configuration } \mathrm{C} \text {, the legs of the subject are } \\
\text { not lying on the bed, so that anterior muscles of the thigh are contracted. }\end{array}$ \\
\hline $\mathrm{Fi}$ & $\begin{array}{l}\text { 2a. Initial ultrasound frame, thicknesses of interest are reported as well as the } \\
\text { detected bone position. } 2 \text { b. Detection of the bone contour on ultrasound frame from the } \\
\text { thresholding in the ROI. 2c. (left) Detected displacement of the bone contour from an } \\
\text { entire ultrasound video. Detected peak delimiting the cycles are shown by the vertical } \\
\text { lines. Hatched area corresponds to conditioning cycles. Each part separated by a vertical } \\
\text { line correspond to a phase of loading/unloading on the thigh. (middle) Computed force } \\
\text { from the force sensor. Detected peaks delimiting the cycles are shown by vertical lines. } \\
\text { (bottom) Computed force displacement curves from peak detection of displacement and } \\
\text { force curves. Corresponding cycles with displacement cycles are used to compute loading } \\
\text { force-displacement curves. }\end{array}$ \\
\hline & $\begin{array}{l}\text { 3a. Experimental force-displacement curves obtained by operator } 1 \text { for one } \\
\text { subject. The two colours correspond to the two cycles of indentation. } 3 \mathrm{~b} \text {. Experimental } \\
\text { force-displacement curves obtained by operator } 1 \text { for one subject. The two colours } \\
\text { correspond to the two cycles of indentation. }\end{array}$ \\
\hline Figu & $\begin{array}{l}\text { Comparison of experimental and numerical force-displacement curves for all } \\
\text { subjects with one operator in both configurations. Thin lines represent configuration R, } \\
\text { wide lines represent configuration C. Experimental curves are represented in dotted lines } \\
\text { and numerical curves in continuous lines. }\end{array}$ \\
\hline Figure 5 & $\begin{array}{l}\text { Typical mechanical response in both the muscle relaxed (R) and muscle } \\
\text { contracted (C) configurations (for subject \#5): 5a. muscle relaxed (R) configuration (top) } \\
\text { initial undeformed state and (bottom) distribution of the maximal principal logarithmic } \\
\text { strain predicted by the FE model 5b. muscle contracted (C) configuration (top) Initial } \\
\text { undeformed state and (bottom) distribution of the maximal principal logarithmic strain } \\
\text { predicted by the FE model 5c. Plot of the maximum principal stress as a function of the }\end{array}$ \\
\hline
\end{tabular}


maximal principal logarithmic strain for one subject, for both operators and for both configurations in the element at mid-distance between the probe and the femur.

\section{List of tables}

Table 1

Clinical data of all subjects and results of the optimisation process on the constitutive parameters of the thigh in both configuration for each operator 